\title{
Spiritual Intelligence of Prospective Teachers In Relation To Their Biographical Factors
}

\author{
Dr. S.S. Kushwaha \\ Asstt. Professor in Education, M.P. Government Degree College, Sikandara Rao (Hathras), India
}

\begin{abstract}
The present research was conducted on prospective teachers to analyze their Spiritual Intelligence in relation to Sex, Caste and SES. For the purpose a sample of 300 (150 male and 150 female) prospective teachers was selected from the B.Ed. Colleges affiliated to Bundelkhand University, Jhansi by using semiprobability sampling techniques. Spiritual Intelligence Scale constructed by Roquiya Zainuddin and Anjum Ahmed was used to collect the data. Results revealed that the there is no significant difference in the mean of spiritual intelligence scores of the male and female prospective teachers. The prospective teachers belong to GEN category scored high on Spiritual Intelligence Scale as compared to the OBC \& SC prospective teachers. The levels of SES of prospective teachers do not cause significant variation in Spiritual intelligence.
\end{abstract}

\section{Introduction}

Psychologists who devised tests to measure rational intelligence termed their measure as "Intelligence Quotient (IQ)", their hypothesis being that higher the IQ more is the rational intelligence. For long, the world gave much importance to Intelligence Quotient. "My son has an IQ of 210" the proud mother would gush. "He's going to be a scientist." Such an attitude was a legacy of the early 20th century.

While the utility of IQ in identifying potential performers is not disputed, according to renowned Psychologists IQ contributes only about $20 \%$ to the factors that determine life success, which leaves $80 \%$ to other forces. This led to further studies in the area of measuring human intelligence. In mid-1990s, Daniel Goleman revealed findings in Neuroscience and Psychology that stressed the importance of Emotional Quotient (EQ). This makes us aware of our feelings and that of others. It gives empathy, motivation, compassion and an ability to respond skillfully to pleasure and pain. Goleman argued that EQ was a basic requirement for the use of IQ. If the areas of our brain that feel are damaged, our ability to think effectively is diminished.

Later, however, authors Zohar and Marshall (2000) introduced a new dimension to human intelligence and coined the term "SQ" for Spiritual Intelligence". People argue that the SQ is the basic foundation for an effective use of EQ and IQ. People also refer to it as the soul's intelligence. While rational, logical thinking gives one's IQ, and the associated habit-bound, pattern recognizing emotive thinking gives one the EQ, the creative, insightful, rule-making, rule breaking thinking with which we reframe and transform our previous thinking gives one the SQ. Just as the whole can be greater than the sum of its parts, SQ allows one to add a larger, deeper and richer context to the present.

In focusing the definition of SI on issues of meaning, Zohar and Marshall (2000) define SI as .the intelligence with which we address and solve problems of meaning and value, the intelligence with which we can place our actions and our lives in a wider, richer, meaning-giving context, the intelligence with which we can assess that one course of action or one life-path is more meaningful than another.

Emmons (2000) draws on Gardner's definition of intelligence and argues that spirituality can be viewed as a form of intelligence because it predicts functioning and adaptation and offers capabilities that enable people to solve problems and attain goals. In other words, spirituality is based on abilities that produce valuable outcomes. Research suggests a relationship between spirituality, life purpose and satisfaction, health, and wellbeing (Kass, Friedman, Leserman, Zuttermeister, \& Benson., 1991).

A few studies that were reviewed showed relationship between SI and education. The findings of Kates (2002) indicated that the major role of a holistic educator is to awaken creativity and SI of learners. Ruiz (2005) gave amazing results about the spiritual dimension in educational leadership. This study explored the use of spirituality by successful educational leaders, to strengthen their effectiveness as it related to schools and their performance. The suggestions of Belousa (2005) include spiritual literacy as a cross-curriculum issue, spiritual paradox as an image that provided balance, and experiential spirituality as a practise to nourish teachers' spirituality. The findings of the study conducted by Jeloudar, Yunus, Roslan and Sharifah (2010) showed a significant relationship between teachers' spiritual intelligence and the six strategies of classroom discipline, including discussion, recognition, involvement, hinting, punishment, and aggression.

It was observed that Spiritual Intelligence was significantly and highly correlated with job performance while cognitive intelligence (IQ) had a very low and insignificant correlation with performance in the work place. 
Each profession requires a certain level of Spiritual intelligence. Without it a person cannot get success in his professional career. Thus, the investigator decided to study the spiritual intelligence of prospective teachers in relation to their Gender, Caste and SES.

\section{Objectives}

1. To study the Spiritual Intelligence of Prospective Teachers of Bundelkhand University in relation to their Gender.

2. To study the Spiritual Intelligence of Prospective Teachers of Bundelkhand University in relation to their Caste.

3. To study the Spiritual Intelligence of Prospective Teachers of Bundelkhand University in relation to their SES.

\section{Hypotheses}

1. There exists no significant difference in spiritual intelligence between male and female prospective teachers.

2. There exists no significant difference in spiritual intelligence among prospective teachers of various caste groups.

3. The levels of socio-economic status of prospective teachers do not cause significant variation in spiritual intelligence.

\section{Method}

\section{Methodology}

The researcher employed the "Descriptive Survey Method".

\section{Sample}

A sample of 300 (150 male and 150 female) prospective teachers was selected from the B.Ed. Colleges affiliated to Bundelkhand University, Jhansi by using semi-probability sampling techniques.

Tool

In order to collect relevant data the Spiritual Intelligence Scale (SIS) constructed by Roquiya Zainuddin and Anjum Ahmed (2011) was used.

\section{Statistical Techniques}

For the analysis of the data the Mean, Standard Deviation and CR test were used.

\section{Results And Discussion}

\subsection{Comparison Of Spiritual Intelligence Of Male And Female Prospective Teachers}

The mean values of Spiritual Intelligence scores for male and female have been found 222.44 and 221.98 respectively, which shows that the both groups have minor difference in their Spiritual Intelligence. Male have higher level of Spiritual Intelligence in comparison to female.

The Statistical evidences are in favour of general observations that the Spiritual Intelligence of male and female are equal. To go into detail and to find out the validity of observation the CR value was calculated and presented in table-1 give below

Table-1 Mean, SD and CR Values of Spiritual Intelligence Scores of Male and Female Prospective Teachers

\begin{tabular}{|l|l|l|l|l|l|l|}
\hline GROUPS & N & M & SD & CR & df & p \\
\cline { 1 - 3 } & 150 & 222.44 & 15.29 & \multirow{2}{*}{0.27} & 298 & $>$ \\
\cline { 1 - 3 } & 150 & 221.98 & 13.68 & & \\
\hline
\end{tabular}

It is evident from the table that the CR-value for male and female prospective teachers was found to be 0.27 , which is insignificant at .05 level for df 298 . Hence, the hypothesis that was framed in this context was accepted and it was concluded that there is no significant difference between the Spiritual Intelligence of male and female prospective teachers. This reveals that male prospective teachers have same level in Inner-self, Interself, Biostoria, Life Perspectives, Spiritual Actualization and Value Orientation in comparison to their counterparts i.e. female prospective teachers. Pictorial representation (vide fig - 1) also support this fact.

The present findings has not corroborates with the findings of Jeloudar et.al. (2010) and Kushwaha (2012) which shows that the female have higher level of spiritual intelligence in comparison to male. 


\subsection{Comparison Of Spiritual Intelligence Of Prospective Teachers Among Various Caste Groups}

In order to find which caste group of prospective teachers is better in Spiritual Intelligence, the mean and $\mathrm{CR}$ values of three groups were calculated and compared. The obtained results are presented in the table- 2

Table-2 Mean, SD and CR Values of Spiritual Intelligence Scores of Various Caste Groups Prospective Teachers

\begin{tabular}{|c|c|c|c|c|c|c|}
\hline GROUPS & $\mathbf{N}$ & M & SD & $t$ & df & $\mathbf{p}$ \\
\hline GEN & 107 & 228.20 & 9.86 & \multirow{2}{*}{1.53} & \multirow{2}{*}{215} & \multirow{2}{*}{$>.05$} \\
\hline OBC & 110 & 225.98 & 11.33 & & & \\
\hline GEN & 107 & 228.20 & 9.86 & \multirow{2}{*}{10.13} & \multirow{2}{*}{188} & \multirow{2}{*}{$<.01$} \\
\hline SC & 83 & 209.49 & 15.49 & & & \\
\hline OBC & 110 & 225.98 & 11.33 & \multirow{2}{*}{8.54} & \multirow{2}{*}{191} & \multirow{2}{*}{$<.01$} \\
\hline SC & 83 & 209.49 & 15.49 & & & \\
\hline
\end{tabular}

A careful perusal of the table-2 reflects that on spiritual intelligence scale, the prospective teachers belong to GEN category scored high as compared to the OBC \& SC prospective teachers. The CR values show that the difference between spiritual intelligence of GEN \& SC and OBC \& SC prospective teachers are statistically significant at .01 level of significance, while the CR value for GEN \& OBC group is statistically insignificant at .05 level of significance. Pictorial representation (vide fig - 1) also support this fact.

Hence, the hypothesis that was framed in this context that 'there exists no significant difference in spiritual intelligence among prospective teachers of various caste groups' was partially rejected and it was concluded that there is significant difference between the Spiritual Intelligence of prospective teachers of various caste groups. This reveals that prospective teachers belong to GEN and OBC category have high level in Inner-self, Inter-self, Biostoria, Life Perspectives, Spiritual Actualization and Value Orientation in comparison to their counterparts i.e. prospective teachers belongs to SC category.

The present study has consonance with the findings of Kushwaha (2012) which shows the significant difference between the Spiritual Intelligence of prospective teachers of various caste groups.

\subsection{Comparison Of Spiritual Intelligence Of Prospective Teachers Among Various Levels Of Socio-Economic} Status

To study the effect of SES on Spiritual Intelligence, first of all, the total sample of prospective teachers was categorized into three groups i.e. high, average and low Socio-Economic Status. To categorize the total sample into three categories as high, average and low, the mean and standard deviation of SES scores were considered. The Prospective teachers who scored $61(\mathrm{M}+1 \sigma) \&$ above on SES Scale were considered as high in SES. The prospective teachers who scored $42(\mathrm{M}-1 \sigma) \&$ below on the SES Scale were considered as low SES, while prospective teachers who scored in between the scores $61 \& 42$ were considered as average in SES. To compare the three groups of prospective teachers on their Spiritual Intelligence, the Critical Ratio Test was applied. The results obtained are shown in the table-3 given below.

Table-3 Mean, S D and CR value of Spiritual Intelligence of High, Average \& Low SES Prospective Teachers

\begin{tabular}{|c|c|c|c|c|c|c|}
\hline GROUPS & $\mathbf{N}$ & $\mathbf{M}$ & SD & $\mathbf{C R}$ & df & $\mathbf{p}$ \\
\hline LOW SES & 56 & 221.64 & 14.20 & \multirow{2}{*}{0.53} & \multirow{2}{*}{233} & \multirow{2}{*}{$>0.05$} \\
\hline AVERAGE SES & 179 & 222.82 & 14.68 & & & \\
\hline LOW SES & 56 & 221.64 & 14.20 & \multirow{2}{*}{0.24} & \multirow{2}{*}{119} & \multirow{2}{*}{$>0.05$} \\
\hline HIGH SES & 65 & 221.03 & 14.33 & & & \\
\hline AVERAGE SES & 179 & 222.82 & 14.68 & \multirow{2}{*}{0.84} & \multirow{2}{*}{242} & \multirow{2}{*}{$>0.05$} \\
\hline HIGH SES & 65 & 221.03 & 14.33 & & & \\
\hline
\end{tabular}

The results of the above table indicate that prospective teachers of high, average or low SES are same in spiritual intelligence. Further among the three groups, average SES prospective teachers either male or female are high in spiritual intelligence than the high and low SES group of prospective teachers. When the three groups of prospective teachers i.e. high, low and average SES are compared in spiritual intelligence, it is found that all the groups have equal spiritual intelligence. As all the C.R. values are found statistically insignificant at .05 level of confidence. Thus, the hypothesis of the study, "the levels of Socio-economic Status of prospective teachers do not cause significant variation in Spiritual intelligence" is accepted. Pictorial representation (vide fig-1) also support this fact.

The relationship between the spiritual intelligence and socio-economic status of prospective teachers was further studied by computing the coefficient of correlation. The Spiritual Intelligence of prospective teachers is significantly related with Socio-Economic Status $(r=0.14, p<.05)$. The correlation reveals the fact that spiritual intelligence does not operate independently but with the increase in scores of SES, spiritual intelligence also increases and vice versa. 


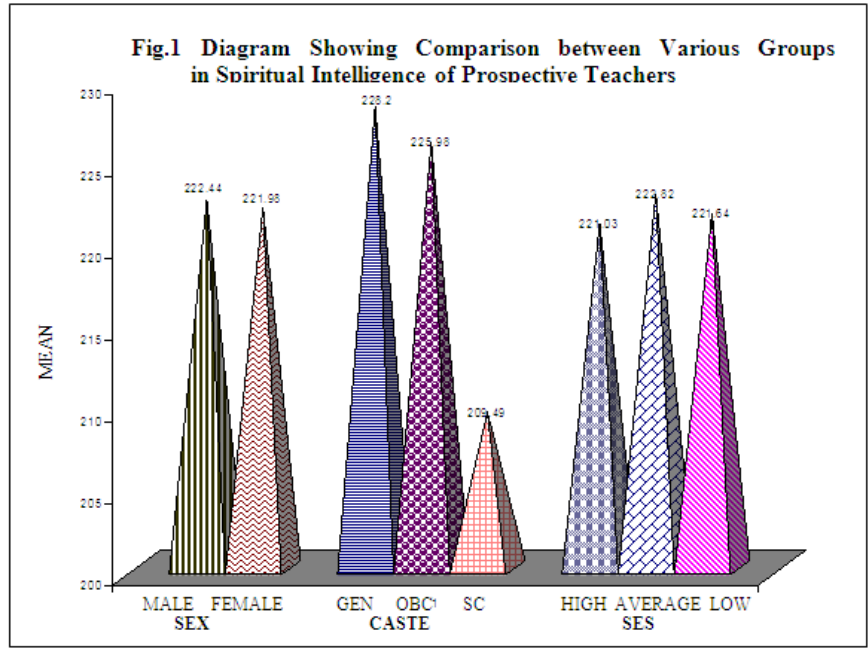

\section{Conclusions}

1. There is no significant difference between the Spiritual Intelligence of male and female prospective teachers.

2. There is a significant difference between the Spiritual Intelligence of prospective teachers of various caste groups. The prospective teachers belong to GEN and $\mathrm{OBC}$ categories have high level of Spiritual Intelligence in comparison to SC category.

3. The prospective teachers of high, average or low SES are same in spiritual intelligence

\section{Educational Implications}

One of the most important aspect of a life is his proper spiritual development. The spiritual development of student is not a spontaneous process but it is give from his childhood. Only a well spiritually developed person can have a static personality, which is essential for better survival in their educational \& professional life.

Training institution can be greatly benefited by making it a point to assess these aspects of student teachers at the time of admission in training institution so that individuals with proper characteristics may be selected for teacher training programmes. Training institutions may also provide such situations to the prospective teachers in training period through which they may develop those characteristics, which are useful in enhancing their spiritual intelligence.

Administrative authorities may also realize the importance of the spiritual intelligence of teachers. The present investigation suggests that educational authorities may concentrate their attention not only on academic qualifications, but also on the spiritual intelligence of prospective teachers at the time of requirements. This Study can provide new ways of thinking for better planning \& effective execution of educational programmes.

\section{References}

[1]. Belousa, I. (2005). Spirituality as a dimension of Education in Latvia. Cited in Dissertation Abstract International. Vol. 66, No. 4, p. 1311 .

[2]. Emmons, Robert (1999). The psychology of ultimate concerns: Motivation and spirituality in personality. New York: Guilford.

[3]. Emmons, Robert (2000a). Is spirituality and intelligence? Motivation, cognition and the psychology of the ultimate concern. International Journal for the Psychology of Religion, 10(1), 3-26.

[4]. Emmons, Robert (2000b). Spirituality and intelligence: Problems and prospects. International Journal for the Psychology of Religion, 10(1), 57-64.

[5]. Gardner, H. (1993). Multiple Intelligences. New York: Basic Books

[6]. Goleman, D. (1995). Emotional intelligence. New York: Bantam Books.

[7]. Jeloudar S. Y., Yunus, A. S., Roslan, S. and Sharifah, M. N. (2010). Teachers' Emotional Intelligence and Its Relation with Classroom Discipline Strategies Based on Teachers and Students' Perceptions. Journal of Psychology, 2(2): 95-102 (2011).

[8]. Kass, J., Friedman, R., Leserman, J., Zuttermeister, P., \& Benson, H. (1991). Health outcomes and new index of spiritual experience. Journal for the Scientific Study of Religion, 30(2), 203-211.

[9]. Kates, M. I. (2002). Awakening creativity and spiritual intelligence: The soul work of holistic educators. University of Toronto, Canada. Cited in Dissertation Abstract International-A, Vol.63, No.12, p. 4202.

[10]. Kushwaha, S.S. (2012). A study of teaching effectiveness of prospective teachers in relation to their emotional and spiritual intelligence, A UGC Minor Project.

[11]. Ruiz, R. (2005). Spiritual Dimension in Educational Leadership. Cited in Dissertation Abstract International. Vol. 66, No. 2, p. 518.

[12]. Sharma, S. (2007). A Study of Job Satisfaction and Teaching Effectiveness of Secondary School Teachers in relation to their Emotional Intelligence. Unpublished Ph.D. Thesis, Bundelkhand University, Jhansi.

[13]. Thorndike, E.L. (1920). Intelligence and its uses. Harper's Magazine, 140, 227-235.

[14]. Zohar, Danah \& Marshall, Ian (2000). SQ: Connecting with our spiritual intelligence. New York: Bloomsbury. 